\title{
Systemic opportunistic fungal infections
}

\author{
R. VANBREUSEGHEM \\ M.D. \\ C. De VRoey \\ D.Sci.
}

Institute of Tropical Medicine, Nationalestraat 155, B-2000, Antwerpen, Belgium

\begin{abstract}
Summary
The clinical manifestations of 'opportunistic' fungal infections in compromised hosts, asthenomycoses, differ from those caused by the same fungus in otherwise normal people. Examples are given on the field of dermatophytoses, aspergillosis, candidiasis and cryptococcosis.
\end{abstract}

\section{Introduction}

It is rather surprising that so many papers, roundtable discussions and symposia have been and still are devoted to 'opportunistic fungus infections' when this description and the term 'opportunistic fungi' have been the subject of much criticism and disagreement. During the Ciba Foundation meeting on 'Systemic Mycoses' in Ibadan, Nigeria, in 1967, it was suggested that the term 'opportunistic infection' was useful to designate and draw attention to an important group of infections, but it is unattractive in various aspects and has not been universally accepted.

Vanbreuseghem and Larsh in 1975 (1977) suggested the term 'asthenomycosis' to describe mycoses due to any species of pathogenic fungus developing as the result of the predisposing role of other diseases, the use of therapeutic agents or other unknown causes.

One of the authors (R.V.) recently maintained that all fungi are opportunistic. The clinical manifestations of dermatophytic infections in compromised hosts differ from those in normal patients. They may be more widespread, may cause deep seated lesions, e.g. Majocchi's granuloma, abscesses and even mycetoma or mycetoma-like lesions. Corticosteroid therapy is a recognized predisposing factor but in many patients no such factors can be demonstrated (Cremer, 1963; Gotz, 1962; Rook, Wilkinson and Ebling, 1968; Thorne and Fusaro, 1971; Burgoon, et al., 1974).

The importance of host factors in patients with chronic extensive dermatophytic infection is described by Hay (1979).

Hadida and Schousboe (1959) used the term 'maladie dermatophytique' to describe the unusual clinical manifestations of dermatophytic infection in a group of patients with as yet unexplained heredi- tary deficiencies. The fungus invades the dermis, subcutaneous tissues, lymph nodes and viscera and is usually fatal. Liautaud (1977) studied the role of host defence mechanisms in 33 published and personal cases. Although unable clearly to delineate any specific immunological factors, there was definite evidence that the factor or factors can be genetically transmitted and are linked with a high degree of inbreeding in the Algerian population.

Strains of Trichophyton violaceum from patients with 'maladie dermatophytique' used in inoculation experiments with white mice were not more pathogenic to the mice than were dermatophytes from other sources. The inference is that the different clinical pictures were a result of abnormalities of host-susceptibility rather than fungal pathogenicity (Courtois, 1977).

Fungi other than dermatophytes also behave differently in compromised hosts - the clinical manifestations may be atypical, the course of a normally chronic infection may be acute, the prognosis is always unfavourable and treatment often unsuccessful.

The systemic mycoses which predominate in Western Europe are aspergillosis, candidiasis and cryptococcosis.

Aspergillosis has a wide variety of clinical manifestations including otomycosis, keratomycosis, sinusitis, colonization of cavities in lung resulting from destructive changes of tuberculosis. These mycoses and even pulmonary aspergilloma are not normally regarded as diseases of compromised hosts and are self-limiting. In compromised hosts, invasion may occur of surrounding tissues and consequently by haematogenous spread to other organs.

The Candida spp. and other yeasts also behave differently in compromised and non-compromised hosts. Candidiasis of the vagina, mucous membranes, skin and nails is commonly seen in otherwise normal patients. Granulomatous candidiasis and invasive or disseminated candidiasis are diseases of compromised hosts. The site of infection and the organisms may be the same in different patients but the host response results in a totally different clinical presentation. The potential severity of Candida in- 
fection of the mucous membranes and skin is well illustrated by Rosman (1979). Cutaneous manifestations of haematogenous spread of Candida have been described by Balandran et al. (1973) and Bodey and Luna (1974). Nodular lesions, located in the dermis, with an erythematous halo were observed in $13 \%$ of patients with acute leukaemia and proved disseminated candidiasis. The lesions were similar in appearance to those seen in allergic drug rashes.

Cryptococcus neoformans may be responsible for acute, subacute and chronic infections in both compromised and non-compromised hosts. The clinical presentations may be the same in both host groups but the frequency of infection is commoner in compromised patients.

The commonest clinical manifestation is meningitis, the portal of entry being the respiratory tract. Pulmonary symptoms are usually transitory and unrecognized. Butler et al. (1964) studied 40 cases of cryptococcal meningitis of which only 20 had a recognizable underlying disease. They did not comment on differences between the 2 categories but generally the evolution of disease is more acute in compromised hosts.

Primary cutaneous cryptococcosis is a very rare event. Lasagni, Riboldi and Berti (1978) reported a patient with apparently primary cutaneous cryptococcosis of about 20 years' duration and without systemic involvement. Multiple skin lesions usually indicated disseminated disease (Sarosi, Silberfarb and Tosh, 1971). Schupbach et al. (1976) believe that cutaneous manifestations of disseminated cryptococcosis are commoner than currently appreciated. In 5 patients the skin lesions were the first indication of underlying cryptococcosis in immunosuppressed patients. The lesions on the extremities initially resembled cellulitis followed by herpes-type vesiculations and ulceration. The initial diagnosis of bacterial cellulitis was disproved by observing yeast cells in direct films and by culturing $C$. neoformans. Increased awareness of cutaneous involvement should result in some cases of disseminated cryptococcosis being diagnosed earlier.

Histoplasma capsulatum, usually regarded as a 'primary pathogen', produces atypical infections in compromised hosts. Daman et al. (1977) reported a third case of disseminated histoplasmosis associated with immunosuppressive therapy which presented as an erysipelas-like eruption and panniculitis. $H$. capsulatum was demonstrated in biopsies.

Other mycoses apparently only occurring in compromised hosts include those caused by Mucor, Alternaria and Geotrichum.

\section{Conclusion}

Although it is generally accepted that there are no symptoms, X-rays or laboratory findings which are specific for a systemic mycosis in a compromised host, better analyses of reported cases indicate that the clinical manifestations differ from those in noncompromised patients. The differences are important as they may lead to earlier diagnosis (Bodey and Luna, 1974; Schupbach et al., 1976).

The symptomatology of asthenomycoses is different from that caused by the same fungi in otherwise normal patients.

\section{References}

Balandran, L., Rothschild, H., Pugh, N. \& Seabury, J. (1973) A cutaneous manifestation of systemic candidiasis. Annals of Internal Medicine, 78, 400.

BODEY, G.P. \& LUNA, M. (1974) Skin lesions associated with desseminated candidiasis. Journal of the American Medical Association, 229, 1466.

Burgoon, C.F., Blank, F., Johnson, W.C. \& GrapPel, S.F. (1974) Mycetoma formation in Trichophyton rubrum infections. British Journal of Dermatology, 90, 115.

Butler, W.T., Alling, D.W., Spickard, A. \& Utz, J.P. (1964) Diagnostic and prognostic value of clinical and laboratory findings in cryptococcal meningitis: A follow-up study of forty patients. New England Journal of Medicine, $270,59$.

Courtols, P.H. (1977) Les dermatophyties semi-profondes et profondes: aperçu de la littérature et expérimentationspersonnelles. Thesis, Institute of Tropical Medicine, Antwerp, Belgium.

CREMER, G. (1963) A special granulomatous form of mycosis on the lower legs caused by Trichophyton rubrum Castellani. Dermatologica, 107, 28.

Daman, L.A., Hashimoto, K., Kaplan, R.J. \& Trent, W.G. (1977) Disseminated histoplasmosis in an immunosuppressed patient. Southern Medical Journal, 70, 355.

Gotz, H. (1962) Die Pilzkrankheiten der Haut durch Dermato phyten, p. 190. Springer Verlag, Berlin.

HADIDA, E. \& Schousboe, A. (1959) Aspects de la maladie dermatophytique. Algérie Médicale, 63, 303.

HAY, R.J. (1979) Failure of treatment in chronic dermatophyte infections. Postgraduate Medical Journal, 55, 608.

LASAGNi, A., Riboldi, A. \& Berti, E. (1978) A case of cryptococcosis of the skin. In: Proceedings of the International Cilag-Chemie Symposium, Flims, Switzerland, January, 24-26. Ed. Ch. Diefenbach, Mykosen, Supplementum $1 / 78$.

Liautaud, B. (1977) Mécanisme de défense au cours des dermatophytoses. Thèse de Doctorat en Sciences Médicales. Université d'Alger, Algeria.

Rook, A., Wilkinson, D.S. \& Ebling, F.J.G. (1968) Textbook of Dermatology, p. 851. Blackwell Scientific Publications, Oxford.

Rosman, N. (1979) Chronic mucocutaneous candidiasis. Postgraduate Medical Journal, 55, 611.

Sarosi, G.A., Silberfarb, P.H. \& Tosh, F.E. (1971) Cutaneous cryptococcosis: a sentinel of disseminated disease. Archives of Dermatology, 104, 103.

Schupbach, C.W., Wheeler, C.E., Briggaman, R.A., WARNER, N.A. \& KANOF, E.P. (1976) Cutaneous manifestations of disseminated cryptococcosis. Archives of Dermatology, 112, 1834.

ThORNe, G. \& FusARo, R. (1971) Subcutaneous Trichophyton rubrum abscesses. Dermatologia, 142, 167.

Vanbreuseghem, R. \& Larsh, H.W. (1977) Conclusions to the round-table on the global problems due to opportunistic fungi. In: Recent Advances in Medical and Veterinary Mycology (Ed. by Iwati, K.), p. 253. University of Tokyo Press. 